\title{
探析基于人性化空间的室内设计
}

\author{
余锋
}

深圳市锐纳装饰设计工程有限公司

DOI:10.32629/btr.v2i8.2399

[摘 要] 目前在我国环境建设的发展中,工程量在日益增加, 室内设计同时也受到很大的重视,然而, 近几年来在我国室内设计 的发展过程当中也存在着和建筑设计领域同样的问题,即创作目的不明确的问题。认真做好室内设计工作, 在满足建筑功能性 同时力求实现人性化, 努力为大众提供良好的工作生活条件。在此,本文将针对室内设计人性化功能空间创造进行简要探讨。

[关键词] 室内设计; 人性化空间; 创造策略

\section{1 室内设计人性化创造的内涵}

现代建筑思想的不断发展, 室内设计更多地考虑现象 学、类型学、符号学、形态学等诸多建筑美学, 坚持以人为 本的理念, 突出人性化特点, 以更好地满足人的生活需要。室 内环境不仅仅是满足人的休息需要, 更是人的一个精神家 园。每个人都有着不同的生活环境, 有着不同的生理需求, 也有着不同的设计要求, 因此, 在室内设计过程中一定要注 重人性化特点, 充分地体现人的主体性, 突出设计的个性化 风格。人性化空间自然就是以服务人生活为最终目的, 注重 个性化的特点。现代社会是以家庭为单位, 每一个家庭的文 化程度各不相同, 他们的工作经历以及生活审美需求也各不 相同, 他们的个性差别也非常大, 因此, 在室内环境设计过程 中不能千篇一律。室内设计应该更好地体现出人的性格特 点、爱好以及他们的工作性质, 更好地体现他们的审美情趣, 打造更富有个性化的居住设计空间。

\section{2 衡量人性化的标准}

人性化的室内设计可以从以下几个方面衡量:

(1) 合理的功能布局。

(2) 视觉上具有一定的美感, 尺度、比例、形式要符合人 的审美标准。

（3）现代技术的创新和地域文化要有机地相结合。

(4)注重多元化、个性化和对弱势群体的特殊关怀。

(5) 注重环保与节能, 使人与社会、自然和谐发展。

\section{3 人性化空间的发展背景}

随着社会的发展, 对人性的认识越加的强烈, 人性思想 也逐渐渗透进建筑思想的发展过程当中, 出现了以人本身固 有的生理以及心理需求为中心的建筑心理学以及行为建筑 学等建筑思想, 为建筑的审美提供了新的参考标准, 使得建 筑设计中逐渐趋向人性化, 尤其是随着人们思想观念以及生 活方式的提升, 再加上科技水平的发展提高, 使得在室内设 计之时, 人性化空间逐渐出现, 提高了人与室内空间环境的 紧密度, 使得居住环境愈加的舒适。

\section{4 人性化空间的特征}

4. 1 个性化。居住空间因年龄、文化程度、经济收入、 工作性质、个性差别、生活经历的不同, 它同时是以家庭为
单元的形式, 因此它在体现个性差别时最为明确。但居住空 间则是个人化的特殊空间, 充分体现主人的性格, 爱好、情 趣、文化、经济收入、工作性质的个人化的空间。

4.2 主体化。这个空间是为人类服务的空间, 是以人为主 体的空间, 因此适宜人体功能是其具备的必要条件之一。

4.3 绿色生态型。主要是以空气污染为话题, 如: 油漆涂 料、石材、家具等在装修过程中产生形成的污染源。

4. 4 体现人类精神需求, 即文化空间氛围。由于文化背 景、个人喜好、工作性质均不同, 营造文化气氛也是现代居 室空间的一个标志性特征。

4.5 居住功能完备。居住空间功能越来越明确, 可分为门 厅、走廊、主卧、次卧、客厅、餐厅、厨房、卫生间、书房、 健身房等等。因此, 现代居住空间具有学习、交友、娱乐、 健身、休闲、工作等一个多功能的使用空间。

\section{5 创造人性化空间的要求分析}

5.1 安全性与实用性的统一。在设计的过程当中, 室内设 计人员首先必须要重视起安全性这一因素, 最大限度的确保 居住者的生命财产安全。在扩大空间或分割空间的时候, 就 要避免出现墙体损坏、电路损坏的等一系列的问题, 避免安 全事故的发生。与此同时, 在设计的过程当中, 还要始终秉承 实用性的设计原则, 避免设计一些毫无意义的设计, 并且所 设计出的空间, 都要有着自身的作用。除此之外, 居住人员往 往会提出一定的设计要求, 例如: 家中有行动不便的老人, 在设计房屋的时候要具备方便、舒适的特点等。因此, 设计 人员在设计的时候也要考虑到这一方面的因素, 在充分满足 居住者的居住要求的同时, 提高室内设计的实用性。

5. 2 环保性与舒适性的统一。现阶段, 随着城市化建设的 不断加快, 给我们的生态环境带来了巨大的影响。我们都知 道, 人是非常崇尚美好的大自然的, 因此, 一名优秀的室内设 计人员, 不应奢求贵气, 而要注重环保。除此之外, 在设计的 时候, 还要确保房屋空间的舒适性, 要具备放松身心的功能。 基于此, 我们就要做好家具、色彩、空间布局等方面的设计 工作, 使得居住者感到非常舒适, 确保其身心健康。举个例子 来说, 可以在是被摆上一些净化空气的植物, 不仅能够让人 感到赏心悦目, 同时还能够营造一个健康的居住环境。 
6 室内设计人性化空间创造的要点分析

6.1家具。通过分析室内空间可知, 室内装饰的灵魂在于 所选择的家具样式及其摆放位置, 选择使用并进行家具装修 的时候, 力求实现人性化设计, 在购买家具中投入大量装修 成本, 切实强化建筑室内档次品质, 此外, 精心布置一些美丽 时尚的小饰品, 完善细节设计。

6. 2 客厅。在设计室内客厅时, 严格遵循 “够用即为美” 的人性化设计原则, 运用细节装饰强化提高客厅品味, 努力 营造出和谐舒适的待客环境, 具体地, 可使用工艺品以及布 艺、书画、藤木及花草、根雕等艺术品装饰客厅, 合理设置 一两个地灯或台灯, 让人居于其中倍感美好。此外, 电视背景 墙可谓是客厅主要装饰, 在设计其时应重视光效应跟吸音等 要点。

6. 3 卧室。进行室内卧室设计中, 基于人性化角度出发, 应注重灯饰层次变化, 认真处理家具摆放, 要求卧室灯饰在 点缀环境的同时满足功能性使用要求, 床头灯以及屋顶吊 灯、背景灯为卧室主要灯具类型。此外, 需根据用户个性特 征与个人喜好设计选择窗帘以及床单。在此应注意, 卧室设 计应重视用户睡眠质量。

6.4 厨房与卫生间。设计厨房时应充分关注厨房油烟问 题这一要点, 由于油烟主要走向为向上, 进而建议较多使用 容易擦洗的装饰材料; 卫生间涉及种类较多且功能复杂程度 高, 其可谓是人们日常工作生活主要功能空间, 在进行设计 时应遵循人性化原则, 主卫建议做好干湿分离, 客卫应明确 具体的干湿分区, 由地面至屋顶将卫生间洗浴部分整个封闭 起来, 积极营造出舒心殹意且温馨浪漫的卫生间环境。

6. 5 其他。在室内设计中, 使用不同的装饰材料能够带给 用户不同感受, 因此应尽量使用能够带给人温暖舒适感觉的 材料, 避免让人产生枯燥冷冰的感觉。植物装饰在人性化空 间设计中有着广泛应用, 众所周知, 植物所拥有功能是很多 的, 包括改善环境以及净化空气等, 其有益于用户身心健康, 芳香类植物能够带给人沁人心脾的温馨感觉, 通过合理搭配 不同质感与色彩、形态的植物能够为用户创造颇具自然感觉 的室内氛围, 使之居住过程中倍感美好。

\section{7 室内设计中人性化空间的创造策略}

7.1 注重布局的合理性以及装饰材料的环保性。在室内 设计的过程当中, 布局工作是最基本的环节, 但是却也是最
重要的工作。因为布局不仅决定着房间的功能, 同时也决定 着人在居住的过程当中是否舒适。举个例子来说: 客厅当中 的沙发怎样摆放才算合理、厨房怎样设计才更加实用等等。 这一系列的问题, 都是设计人员在布局的过程当中所需要考 虑的问题。除此之外, 对于装修材料的使用, 我们必须要考虑 到环保性、安全性方面的因素。现阶段, 很多装修材料当中 都含有大量的有毒有害物质, 严重威胁着人体健康。在这种 情况下, 我们就必须要仔细篎选材料, 避免用一些劣质材料。 例如: 很多墙漆当中含有大量苯, 严重影响着我们的健康, 因此我们必须要重视起这一问题。

7.2利用辅助性因素打造舒适空间。充分的借助辅助性 因素, 包括灯光、色彩等等, 能够在很大程度上提高居住的舒 适感以及温馨感。基于此, 设计人员在设计的时候, 就要学习 应用这一系列的因素, 在充分的结合居住者的生活习惯的同 时, 使得设计更加具有个性。

7. 3坚持创新。随着时代的不断发展, 以往传统的设计理 念, 必然无法满足当前设计行业发展所需, 在这种情况下, 室 内设计行业要想确保可持续发展, 就必须要积极的进行创新, 进而带给居住者更加独具一格的居住体验。可以说, 创新是 室内设计人员毕生追求的目标。

\section{8 结束语}

室内设计是一项大工程, 室内设计工作者不但要满足居 住者的审美需求, 同时也要保证设计的实用性。在中国经济 与文化迅猛发展的今天, 以往只需要提供住宿功能的室内环 境以无法满足人们的需求, 人们对于居住空间给予了更多期 望。因此, 室内设计者应该为居住者提供兼具美观与实用性 的人性化空间设计, 保证居住者可以在一个舒适且功能性强 的空间中生活, 让人们能够时刻体会到室内空间的人性化。

[参考文献]

[1]邢东.室内设计中人性化空间的创造的重要性研究 [J].科技展望,2015(10):34。

[2]常伟.谈家居设计中的人性化和个性化 [J].人民论 坛,2015(33):177-178.

[3]马俊峰.论室内设计中人性化空间的创造初探[J].江 西建材,2017(19):38+42.

[4]丁石雄,李卓染. 现代室内设计中人性化空间室内设 计应用研究[J].建材与装饰,2018(03):95. 